PENGARUH MEDIA TANAM DAN INTENSITAS NAUNGAN TERHADAP PERTUMBUHAN BIBIT KOPI ARABIKA (Coffea arabica L.) SEBAGAI BAHAN TANAMAN POLA AGROFORESTRI Milla Artina, Suhardjadinata, Dedi Natawijaya, dan Aditya Hani

\title{
PENGARUH MEDIA TANAM DAN INTENSITAS NAUNGAN TERHADAP PERTUMBUHAN BIBIT KOPI ARABIKA (Coffea arabica L.) SEBAGAI BAHAN TANAMAN POLA AGROFORESTRI
}

(The Effect of Planting Media and Shade Intensity on The Growth of Coffee Seeds (Coffea arabica L.)) *Milla Artina1, *Suhardjadinata1, *Dedi Natawijaya1, dan/and *Aditya Hani²

1) Jurusan Agroteknologi, Fakultas Pertanian, Universitas Siliwangi

Jl Siliwangi No.24 Kotak Pos 164 Kode pos 46115 Tasikmalaya, Indonesia

${ }^{2}$ Balai Penelitian dan Pengembangan Teknologi Agroforestry Jl. Ciamis-Banjar km. 04 Ciamis 46271, Telp. 0265 771352, Jawa Barat, Indonesia

e-mail: adityahani@gmail.com

Naskah masuk: 19 Agustus 2021; Naskah direvisi: 19 Oktober 2021; Naskah diterima: 25 November 2021

\section{ABSTRACT}

The productivity of arabica coffee (Coffea arabica L.) in agroforestry system in Indonesia is still relatively low. One of the things that need to be considered to increase the productivity of arabica coffee is during nurseries. Planting media and shade density need to be considered in seedling techniques. This study aimed to determine the type of planting media and the shade intensity for the arabica coffee seedlings. The experiment was carried out using a split plot design consisting of two factors. Shade density as the main factor consists of 3 levels and the type of planting media as subplots consists of 4 levels, repeated 3 times. The results showed that the treatment interaction between shade and growing media gave significant differences between treatments on the parameters of height, diameter and root dry weight. Arabica coffee seedlings can reach the largest height of $11.11 \mathrm{~cm}-11.88 \mathrm{~cm}$ at $80 \%$ shade density on soil media or a mixture of soil and manure or soil and husk charcoal. Soil media mixed with manure (3:1) can produce the largest number of leaves and dry weight of top biomass, that are 10.44 and $1.75 \mathrm{~g}$ repectively

Keywords: agroforestry, arabica coffee, media, shade

\begin{abstract}
ABSTRAK
Produktivitas kopi arabika (Coffea arabica L.) pada pertanaman agroforestry di Indonesia masih tergolong rendah. Salah satu hal yang perlu diperhatikan untuk menaikan produktivitas kopi arabika adalah pada saat pembibitan. Salah satu yang perlu diperhatikan dalam pembibitan adalah jenis media tanam dan pemberian naungan. Penelitian ini bertujuan untuk mengetahui media tanam dan kerapatan naungan yang terbaik untuk pertumbuhan bibit kopi arabika.. Penelitian menggunakan metode eksperimen rancangan petak terbagi (split plot design) yang terdiri dari dua faktor. Naungan sebagai faktor utama terdiri dari 3 taraf intensitas naungan dan jenis media tanam sebagai anak petak terdiri dari 4 taraf. Setiap kombinasi diulang sebanyak 3 kali. Hasil penelitian menunjukkan bahwa interaksi perlakuan antara naungan dan media tanam memberi perbedaan yang nyata pada parameter tinggi, diameter dan berat kering akar. Bibit kopi arabika dapat mencapai tinggi terbesar $11,11 \mathrm{~cm}-11,88 \mathrm{~cm}$ dengan perlakuan pemberian naungan $80 \%$ pada media tanah atau campuran tanah dan pupuk kandang atau arang sekam. Media tanah yang dicampur dengan pupuk kandang ( 3:1) dapat menghasilkan jumlah daun dan berat kering biomasa atas terbesar masing-masing sebesr 10,44 dan 1,75 g di persemaian.
\end{abstract}

Kata kunci: agroforestri, kopi arabika, media, naungan

\section{PENDAHULUAN}

Salah satu model agroforestri yang berkembang luas di Indonesia adalah agroforestri antara tanaman kehutanan dengan tanaman kopi. Tanaman kopi tumbuh baik di bawah naungan, bahkan keberadaan tanaman penaung berupa tanaman kehutanan dapat melindungi kopi dari kekeringan Agroforestri kopi yang dikembangkan petani berperan dalam: konservasi tanah dan air, keanekaragaman hayati, penambahan unsur hara, pengendalian iklim mikro, penambahan cadangan karbon, mengurangi serangan hama dan penyakit serta peningkatan pendapatan

*Kontribusi penulis: Milla Artina, Suhardjadinata, Dedi Natawijaya, dan Aditya Hani sebagai kontributor utama 
masyarakat (Supriadi \& Pranowo, 2015). Indonesia memiliki jenis kopi robusta, kopi arabika dan liberika. Pada tahun 2019, produksi kopi di Indonesia mengalami penurunan, yaitu dari 756.051 ton pada tahun 2018 menjadi 752.511 ton dengan dominasi kopi jenis robusta sebesar 71,51\% (Direktorat Jenderal Perkebunan, 2020). Pada umumnya jenis pohon penaung yang digunakan adalah jenis pohon yang mempunyai nilai ekonomi tinggi seperti durian hutan, dadap serta sengon (Priyadarshini, Hairiah, Suprayogo, \& Baon, 2011). Kopi juga dapat tumbuh baik apabila ditanam di bawah pohon berkayu jenis cempaka, afrika, mahoni dan sengon (A. M. Pratiwi, Kaskayo, Herwanti, \& Qurniati, 2019). Kopi dengan penaung pohon jenis legum mampu menghasilkan seresah dengan kualitas yang lebih baik dibandingkan kopi monokultur maupun seresah hutan (Qifli, Hairiah, \& Suprayogo, 2014).

Salah satu kebutuhan kopi dunia yang cukup tinggi adalah kopi jenis arabika. Luasan dan produksi kopi arabika di Indonesia masih perlu ditingkatkan lagi karena potensi pasar serta harga jual yang tinggi. Sebagian petani masih menggunakan bibit yang berasal dari anakan alam serta belum memperhatikan kualitas bibit, sehingga produktivitas kopi tidak optimal. Kopi yang dibudidayakan secara agroforestri maka bibit perlu disiapkan dengan mengetahui intensitas cahaya matahari yang dibutuhkan. Pemberian naungan di persemaian diharapkan akan meningkatkan daya adaptasi kopi ketika ditanam di lapangan menggunakan pola agroforestri. Naungan juga berfungsi menyediakan intensitas cahaya yang sesuai dengan kebutuhan bibit, suhu, kelembaban dan melindungi kerusakan dari hama dan penyakit (Harahap, Nurhidayah, \& Saputra, 2015).

Kualitas bibit juga dipengaruhi oleh media tanam bibit yang tepat. Media yang digunakan sebaiknya yang mudah diperoleh, banyak tersedia serta harga murah. Media tanam yang mengandung bahan organik mempunyai keunggulan karena dapat menyediakan unsur hara, bobot lebih ringan, memiliki pori-pori mikro dan makro yang hampir seimbang sehingga sirkulasi udara cukup baik serta memiliki daya serap air tinggi (Harahap et al., 2015) . Salah satu jenis bahan organik yang dapat digunakan adalah cocopeat. Cocopeat merupakan limbah proses pembuatan serat sabut kelapa, sehingga penggunaan cocopeat dapat mengurangi limbah industri sekaligus meningkatkan nilai ekonominya. Media tanam cocopeat mempunyai kemampuan mengikat air yang cukup baik (Pratiwi, Simanjuntak, \& Banjarnahor, 2017). Media tanam lainnya yang dapat digunakan adalah dari limbah pertanian yaitu arang sekam. Arang sekam memiliki kandungan karbon yang tinggi serta memiliki sifat porositas tinggi sehingga membuat media menjadi gembur (Bariyyah, Suparjono, \& 
Usmadi, 2015). Pupuk kandang dapat digunakan sebagai campuran media tanam karena mempunyi kandungan unsur hara yang lengkap, berperan menambah kadar humus tanah dan dapat mendorong kehidupan mikroba pengurai tanah (Sitanggang, Isnan, \& Saputra, 2015). Pupuk kandang juga dapat mengurangi penggunaan pupuk kimia sehingga mengurangi emisi yang dihasilkan selama pembibitan. Penelitian ini bertujuan untuk mengetahui jenis media dan tingkat naungan yang terbaik untuk menghasilkan bibit kopi arabika yang berkualitas.

\section{METODE PENELITIAN}

\section{A. Bahan dan Alat}

Alat yang digunakan untuk penelitian ini adalah alat pengukur (penggaris, timbangan) dan alat pendukung lainnya. Bahan yang digunakan pada penelitian ini adalah benih kopi arabika varietas Gayo yang diperoleh dari Balai Penelitian dan Pengembangan Teknologi Agroforestri, tanah, pupuk kandang, arang sekam, cocopeat, paranet kerapatan $80 \%$, paranet kerapatan 50\%, dan polybag. Benih disemaikan terlebih dahulu di media tanah campur pupuk kandang. Setelah benih berkecambah dan memiliki 2 (dua) daun selanjutnya dipindahkan ke polibag sesuai perlakuan.

\section{B. Prosedur Penelitian}

Penelitian dilaksanakan di persemaian Balai Penelitian dan Pengembangan Teknologi
Agroforestri Ciamis, dengan ketinggian \pm 137 meter di atas permukaan laut. Percobaan dilaksanakan pada bulan September sampai bulan Desember 2019. Penelitian menggunakan metode eksperimen dengan rancangan petak terbagi (split plot design) (Gomez \& Gomez, 1995) yang terdiri atas:

Faktor utama: kerapatan naungan menggunakan paranet yang terdiri dari 3 taraf yaitu:

$$
\begin{aligned}
\mathrm{n}_{0}= & \text { kerapatan naungan } 0 \% \quad \text { (tanpa } \\
& \text { diberi naungan) } \\
\mathrm{n}_{1}= & \text { kerapatan naungan } 50 \% \\
\mathrm{n}_{2}= & \text { kerapatan naungan } 80 \%
\end{aligned}
$$

Faktor anak petak: media tanam yang terdiri dari 4 taraf yaitu:

$$
\begin{array}{ll}
\mathrm{m}_{0}=\operatorname{tanah} \\
\mathrm{m}_{1}=\text { tanah }+ \text { pupuk kandang } & (3: 1, \mathrm{v} / \mathrm{v}) \\
\mathrm{m}_{2}=\text { tanah }+ \text { arang sekam } & (3: 1, \mathrm{v} / \mathrm{v}) \\
\mathrm{m}_{3}=\text { tanah }+ \text { cocopiet } & (3: 1, \mathrm{v} / \mathrm{v})
\end{array}
$$

Tabel (Table) 1. Kombinasi perlakuan kerapatan naungan dan media tanam (Combination of shade density treatment and growing media)

\begin{tabular}{ccccc}
\hline $\begin{array}{c}\text { Petak utama } \\
\text { Kerapatan } \\
\text { naungan }\end{array}$ & \multicolumn{4}{c}{$\begin{array}{c}\text { Anak petak } \\
\text { Media tanam }(\mathrm{m}) / \text { Growing } \\
\text { media }\end{array}$} \\
\cline { 2 - 5 }$(\mathrm{n}) /$ shade density & $\mathrm{m}_{1}$ & $\mathrm{~m}_{2}$ & $\mathrm{~m}_{3}$ & $\mathrm{~m}_{4}$ \\
\hline $\mathrm{n}_{0}$ & $\mathrm{n}_{0} \mathrm{~m}_{1}$ & $\mathrm{n}_{0} \mathrm{~m}_{2}$ & $\mathrm{n}_{0} \mathrm{~m}_{3}$ & $\mathrm{n}_{0} \mathrm{~m}_{4}$ \\
$\mathrm{n}_{1}$ & $\mathrm{n}_{1} \mathrm{~m}_{1}$ & $\mathrm{n}_{1} \mathrm{~m}_{2}$ & $\mathrm{n}_{1} \mathrm{~m}_{3}$ & $\mathrm{n}_{1} \mathrm{~m}_{4}$ \\
$\mathrm{n}_{2}$ & $\mathrm{n}_{2} \mathrm{~m}_{1}$ & $\mathrm{n}_{2} \mathrm{~m}_{2}$ & $\mathrm{n}_{2} \mathrm{~m}_{3}$ & $\mathrm{n}_{2} \mathrm{~m}_{4}$ \\
\hline
\end{tabular}

Data hasil pengamatan dianalisis dengan analisis sidik ragam pada taraf nyata $5 \%$ atau dengan selang kepercayaan 95\%. Apabila terdapat perbedaan yang nyata antar perlakuan selanjutnya dilakukan uji lanjut Duncan. 


\section{HASIL DAN PEMBAHASAN}

\section{A. Hasil}

Pertumbuhan bibit kopi arabika di persemaian sampai umur 3 (tiga) bulan menunjukkan perbedaan yang nyata antar perlakuan.

Hasil analisis varian pengaruh naungan dan media tanam disajikan pada Tabel 2.

Tabel (Table) 2. Hasil analisis varian perlakuan naungan dan media tanam terhadap pertumbuhan bibit kopi arabika di persemaian (Results of analysis of variants of shade treatment and planting media on the growth of arabica coffee seedlings in nurseries)

\begin{tabular}{|c|c|c|c|c|c|}
\hline $\begin{array}{c}\text { Sumber keragaman } \\
\text { (Source of } \\
\text { variance) }\end{array}$ & $\begin{array}{l}\text { Jumlah } \\
\text { kuadrat } \\
\text { (Sum of } \\
\text { square) }\end{array}$ & $\begin{array}{c}\text { Derajat bebas } \\
\text { (Degree of } \\
\text { freedom) }\end{array}$ & $\begin{array}{l}\text { Kuadrat tengah } \\
\text { (Mean of } \\
\text { square) }\end{array}$ & $\begin{array}{l}\text { F.Hitung } \\
\quad(F . \\
\text { Calculate })\end{array}$ & Sig. \\
\hline \multicolumn{6}{|l|}{ Tinggi (Height) } \\
\hline Naungan*Media & 5,488 & 6 & 0,92 & 4,48 & $0,004 *$ \\
\hline Naungan & 199,24 & 2 & 99,62 & 488,26 & $0,000 *$ \\
\hline Media & 3,32 & 3 & 1,10 & 5,43 & $0,006^{*}$ \\
\hline Ulangan & 438 & 2 & 0,22 & 1,07 & 0,359 \\
\hline \multicolumn{6}{|l|}{$\sum$ Daun (Leaf) } \\
\hline Naungan*Media & 4,54 & 6 & 0,76 & 2,04 & 0,103 \\
\hline Naungan & 0,108 & 2 & 0,054 & 0,145 & 0,866 \\
\hline Media & 19,86 & 3 & 6,62 & 17,88 & $0,000 *$ \\
\hline Ulangan & 0,170 & 2 & 0,085 & 0,23 & 0,797 \\
\hline \multicolumn{6}{|l|}{ Diameter } \\
\hline Naungan*Media & 0,03 & 6 & 0,001 & 2,79 & $0,036^{*}$ \\
\hline Naungan & 0,02 & 2 & 0,001 & 4,91 & $0,017 *$ \\
\hline Media & 0,012 & 3 & 0,004 & 19,49 & $0,000 *$ \\
\hline Ulangan & 0,002 & 2 & 0,001 & 4,842 & $0,037 *$ \\
\hline \multicolumn{6}{|c|}{ Berat kering akar (Root dry weight) } \\
\hline Naungan*Media & 0,201 & 6 & 0,034 & 3,83 & $0,009 *$ \\
\hline Naungan & 0,199 & 2 & 0,10 & 11,36 & $0,000 *$ \\
\hline Media & 0,340 & 3 & 0,116 & 13,26 & $0,000 *$ \\
\hline Ulangan & 0,001 & 2 & 0,000 & 0,029 & 0,972 \\
\hline \multicolumn{6}{|c|}{ Berat kering biomasa atas (Top biomass dry weight) } \\
\hline Naungan*Media & 1,23 & 6 & 0,21 & 2,53 & 0,051 \\
\hline Naungan & 0,10 & 2 & 0,05 & 0,61 & 0,553 \\
\hline Media & 8,67 & 3 & 2,89 & 35,55 & $0,000 *$ \\
\hline Ulangan & 0,21 & 2 & 0,10 & 1,26 & 0,30 \\
\hline
\end{tabular}

Interaksi antara perlakuan intensitas naungan dan jenis media berpengaruh nyata terhadap parameter tinggi, diameter dan berat kering akar (Tabel 2). Interaksi perlakuan yang menghasilkan pertumbuhan terbaik dapat diketahui dari hasil uji lanjut Duncan (Tabel 3).
Parameter pertumbuhan yang tidak dipengaruhi interaksi antar perlakuan namun lebih dipengaruhi oleh faktor tunggal yaitu jumlah daun dan berat kering batang+daun. Hasil uji lanjut pengaruh tunggal yang memberikan pertumbuhan terbaik (Tabel 4). 
Tabel (Table) 3. Hasil uji lanjut Duncan pengaruh interaksi tingkat naungan dan jenis media (Duncan's further test results influence the interaction of shade level and media type)

\begin{tabular}{|c|c|c|c|}
\hline Perlakuan (Treatment) & $\begin{array}{l}\text { Tinggi }(\text { H eight }) \\
(\mathrm{cm})\end{array}$ & Diameter $(\mathrm{cm})$ & $\begin{array}{l}\text { Berat kering akar } \\
(\text { Root dry weight })(\mathrm{g})\end{array}$ \\
\hline $\begin{array}{l}\text { N2M0 (naungan } 80 \% \text {,media tanah } / \text { shade density } 80 \% \\
\text {, soil media) }\end{array}$ & $11,88 \mathrm{a}$ & $0,257 \mathrm{bc}$ & $0,245 \mathrm{~b}$ \\
\hline $\begin{array}{l}\text { N2M1 (naungan } 80 \% \text {, campuran media tanah dan } \\
\text { pupuk kandang / shade density } 80 \% \text {, mixed media of } \\
\text { soil and manure) }\end{array}$ & $11,88 \mathrm{a}$ & $0,257 \mathrm{bc}$ & $0,263 \mathrm{~b}$ \\
\hline $\begin{array}{l}\mathrm{N} 2 \mathrm{M} 2 \text { (naungan } 80 \% \text {, campuran media tanah dan } \\
\text { arang sekam/shade density } 80 \% \text {, mixed media soil } \\
\text { and husk charcoal) }\end{array}$ & 11,11 a & $0,260 \mathrm{bc}$ & $0,322 b$ \\
\hline $\begin{array}{l}\text { N2M3 (naungan } 80 \% \text {, campuran media tanah dan } \\
\text { cocopeat } / \text { shade density } 80 \% \text {, mixed media soil and } \\
\text { cocopeat) }\end{array}$ & $10,22 \mathrm{~b}$ & $0,237 \mathrm{c}$ & $0,193 \mathrm{~b}$ \\
\hline $\begin{array}{l}\text { N1M1 (naungan } 50 \% \text {, campuran media tanah dan } \\
\text { pupuk kandang/ shade density } 50 \% \text {, mixed media } \\
\text { soil and manure) }\end{array}$ & $8,62 \quad \mathrm{c}$ & $0,277 \mathrm{abc}$ & $0,661 \mathrm{a}$ \\
\hline $\begin{array}{l}\mathrm{N} 1 \mathrm{M} 2 \text { (naungan } 50 \% \text {, campuran media tanah dan } \\
\text { arang sekam/shade density } 50 \% \text {, mixed media soil } \\
\text { and husk charcoal }\end{array}$ & $7,75 \quad d$ & $0,249 \mathrm{c}$ & $0,362 \mathrm{~b}$ \\
\hline $\begin{array}{l}\mathrm{N} 1 \mathrm{M} 3 \text { (naungan } 50 \% \text {, campuran media tanah dan } \\
\text { cocopeat/ shde density } 50 \% \text {, mixed media soil and } \\
\text { cocopeat) }\end{array}$ & $7,54 \mathrm{~d}$ & $0,243 \mathrm{c}$ & $0,257 \mathrm{~b}$ \\
\hline $\begin{array}{l}\text { N1M0 (naungan } 50 \% \text {, media tanah/ shade density } \\
50 \% \text {, soil media) }\end{array}$ & $7,30 \quad \mathrm{~d}$ & $0,296 \mathrm{ab}$ & $0,359 \mathrm{~b}$ \\
\hline $\begin{array}{l}\text { N0M3 (tanpa naungan, campuran media tanah dan } \\
\text { cocopeat } \text { without shade, mixed media soil and } \\
\text { cocopeat) }\end{array}$ & 5,75 e & $0,253 \mathrm{c}$ & $0,210 \mathrm{~b}$ \\
\hline $\begin{array}{l}\text { N0M1 (tanpa naungan, campuran media tanah dan } \\
\text { pupuk kandang/without shade, mixed media soil and } \\
\text { manure) }\end{array}$ & $5,55 \mathrm{e}$ & $0,302 \mathrm{a}$ & $0,563 \mathrm{a}$ \\
\hline $\begin{array}{l}\text { N0M2 (tanpa naungan, media campuran tanah dan } \\
\text { arang sekam/without shade, mixed media soil and } \\
\text { husk charcoal) }\end{array}$ & $5,54 \quad \mathrm{e}$ & $0,264 a b c$ & $0,355 \mathrm{~b}$ \\
\hline $\begin{array}{l}\text { N0M0 (tanpa naungan, media tanah/ without shade, } \\
\text { soil media) }\end{array}$ & 5,36 e & $0,258 \mathrm{bc}$ & $0,541 \mathrm{a}$ \\
\hline
\end{tabular}

Tinggi bibit terbaik ditunjukan pada perlakuan pemberian naungan $80 \%$ dengan menggunakan media tanah (M0), tanah + pupuk kandang (M1), tanah + sekam bakar (M2) (Tabel 3). Diameter tanaman terbaik ditunjukan pada perlakuan tanpa pemberian naungan serta media tanah+pupuk kandang. Berat kering akar terbesar ditunjukan pada perlakuan N1M1 dan N0M0.

$$
\text { Hal ini menunjukkan bahwa }
$$
perkembangan akar terbaik ditunjukkan pada perlakuan naungan 50\% dengan media tanah+pupuk kandang dan perlakuan tanpa naungan dengan media tanah. 
Tabel (Table) 4. Hasil uji lanjut Duncan faktor tunggal yang mempengaruhi pertumbuhan bibit kopi arabika (Duncan's further test results of single factors that affect the growth of arabica coffee seedlings)

\begin{tabular}{|c|c|c|}
\hline Perlakuan (Treatment) & $\sum$ Daun (leaf) & $\begin{array}{l}\text { Berat kering biomasa atas } \\
\text { (Top biomass dry weight) (g) }\end{array}$ \\
\hline Tanah+pupuk kandang (soil + manure) & $10,44 \mathrm{a}$ & $1,75 \mathrm{~g} \mathrm{a}$ \\
\hline Tanah (soil) & $9,90 \mathrm{ab}$ & $1,04 \mathrm{~g} \quad \mathrm{~b}$ \\
\hline Tanah+arang sekam (soil + husk charcoal) & $9,44 \quad b$ & $0,75 \mathrm{~g} \quad \mathrm{c}$ \\
\hline Tanah + cocopeat $($ soil + cocopeat $)$ & 8,42 & $0,42 \mathrm{~g}$ \\
\hline
\end{tabular}

Keterangan (Remarks): Nilai yang dikuti oleh huruf yang berbeda a, b atau c pada kolom yang sama menunjukkan perbedaan yang nyata (taraf uji 5\%) menurut uji beda berganda Duncan (Values followed by different letters $a, b$ or $c$ in the same column show significant differences (5\% test level) according to Duncan's multiple difference test)

Perlakuan media tanah+pupuk kandang menghasilkan pertumbuhan jumlah daun dan berat kering biomasa atas terbesar (Tabel 4). Hasil yang sama ditunjukan oleh Sari, Marliah, \& Hereri, (2019) yang menyatakan bahwa penggunaan media tanah+pupuk kandang dapat menghasilkan pertumbuhan bibit kopi yang lebih optimal.

\section{B. Pembahasan}

Pertumbuhan bibit kopi arabika dipengaruhi oleh tingkat naungan dan media tanam yang digunakan, terutama tinggi bibit kopi. Pertumbuhan tinggi bibit kopi terbaik ditunjukkan pada perlakuan N2M0, N2M1 dan N2M2. Hasil tersebut menunjukkan bawa penggunaan naungan dengan intensitas sebesar $80 \%$ baik menggunakan media tanah, campuran tanah dan pupuk kandang $(3: 1, \mathrm{v} / \mathrm{v})$ maupun campuran tanah dan arang sekam $(3: 1, \mathrm{v} / \mathrm{v})$ menghasilkan tinggi bibit yang terbaik. Naungan menyebabkan bibit mengalami etiolasi sehingga bibit tanaman lebih tinggi (Alridiwirsah, Hamidah, Erwin, \& Muchtar, 2015). Selain itu, aktivitas hormon auksin akan meningkat terutama di bagian pucuk tanaman akibat terbatasnya cahaya matahari, sehingga menyebabkan pemanjangan tanaman (Nurkhasanah, Wicaksono, \& Widaryanto, 2013). Naungan juga dapat menekan laju evaporasi pada tanah dan transpirasi pada tanaman sehingga tidak mengalami kekeringan (Saleh \& Jayanti, 2017). Keberadaan naungan juga dapat melindungi sel daun muda dari kerusakan karena intensitas sinar matahari yang tinggi (Anam, 2015). Perbedaan jenis media pada tingkat naungan $50 \%$ tidak memberikan perbedaan yang nyata pada parameter tinggi. ketiga jenis media yang digunakan mempunyai aerasi dan drainase yang baik sehingga menyediakan oksigen yang cukup untuk meningkatkan kemampuan akar beroksidasi (Sembiring, Sipayung, \& Irsal, 2018).

Parameter pertumbuhan bibit yang dipengaruhi secara nyata oleh perbedaan perlakuan adalah diameter. Diameter terbesar ditunjukan oleh kombinasi perlakuan tanpa naungan dan media tanam tanah dan pupuk

\section{2}


kandang (3:1). Intensitas cahaya matahari yang tinggi (tanpa naungan) akan meningkatkan jumlah stomata pada bibit kopi sehinga meningkatkan aktifitas fotosintesis (Suherman, 2015). Campuran media tanah dan pupuk kandang menyediakan unsur hara yang lebih tinggi dibandingkan campuran tanah dengan media arang sekam dan cocopeat serta mempunyai nilai $C / N$ ratio lebih rendah sehingga unsur hara mudah terserap oleh tanaman (Danu \& Kurniaty, 2013; Syahadat \& Aziz, 2012). Unsur hara yang cukup serta dengan sifat fisik, kimia dan biologi media tanah yang baik akan memacu pertumbuhan batang tanaman (Suherman, 2015).

Perlakuan N1M1 (naungan 50\% dengan media tanah+pupuk kandang $(3: 1, \mathrm{v} / \mathrm{v}))$ menghasilkan berat kering akar yang terbesar walaupun tidak berbeda nyata dengan perlakuan N0M1 dan N0M0. Pramono \& Siregar, (2015) menyebutkan bahwa pemberian naungan akan memacu pertumbuhan akar dibandingkan tannpa naungan pada bibit di persemaian. Safitri, Purbajanti, \& Karno (2020) menyatakan bahwa perkembangan akar distimulus oleh adanya karbohidrat yang berasal dari daun dan batang tanaman. Unsur hara yang cukup yang berasal dari pupuk kandang serta intensitas cahaya yang tidak berlebihan akan menghasilkan proses metabiolisme yang optimal yang selanjutnya digunakan untuk pertumbuhan vegetatif tanaman antara lain perakaran.
Beberapa parameter pertumbuhan bibit kopi arabika dipersemaian lebih dipengaruhi oleh faktor tunggal dibandingkan dengan kombinasi perlakuan. Parameter jumlah daun dan berat kering biomassa atas bibit kopi arabika di persemaian lebih dipengaruhi oleh faktor tunggal yaitu media tanam. Media tanah dan pupuk kandang menghasilkan jumlah daun terbanyak (10 daun per tanaman). Hasil ini menunjukkan bahwa keberadaan pupuk kandang dapat berperan dalam penyediaan unsur hara yang digunakan oleh tanaman dalam proses metabolisme. Hasil dari proses metabolisme tersebut yang digunakan untuk pembentukan daun maupun bagian vegetatif lainnya (Muningsih, Putri, \& Subantoro, 2018). Pupuk kandang yang dicampur dengan tanah akan mengalami pelapukan melalui proses oksidasi enzimatik oleh mikroorganisme sehingga menghasilkan unsur hara yang mudah diserap oleh tanaman sebagai bahan baku proses metabolisme (Wachjar, Setiadi, \& Mardhikanto, 2002).

Berdasarkan hasil penelitian di atas, maka penyediaan bibit kopi untuk pola tanam agroforestry dapat dilakukan dengan menyediaan bibit kopi yang menggunakan media tanah (M0), tanah+ pupuk kandang (M1), tanah+sekam bakar dst dengan intensitas naungan $80 \%$. Pengembangan tanaman kopi yang di tanam dengan pola agroforestri dapat di tanam di bawah beberapa tegakan hutan sperti: gamal (Gliricidia cepium), dadap (Erythrina 
Jurnal Perbenihan Tanaman Hutan

Vol.9 No 2 Desember 2021: 87-95

p-ISSN : 2354-8568

e-ISSN : 2527-6565

variegata), cempaka (Michelia campaca), sengon (Falcataria mollucana) yang dapat berperan sebagai pelindung sekaligus berperan positif dalam siklus hara tanah dan konservasi air (Evizal, Tohari, Prijambada, \& Widada, 2012).(Mahasidhi \& Prijono, 2021). Penggunaan pohon penaung dalam budidaya kopi sebagai bentuk penerapan good agricultural practices yang membuat tanaman kopi lebih sehat, lestari secara produksi dan lingkungan (Adinandra \& Pujianto, 2020).

\section{KESIMPULAN}

Interaksi perlakuan antara naungan dan media tanam berpengaruh nyata terhadap tinggi, diameter dan berat kering akar bibit kopi. Pertumbuhan bibit kopi terbaik di persemaian dapat dilakukan dengan menggunakan media tanam berupa campuran tanah dengan pupuk kandang $(3 ; 1, \mathrm{v} / \mathrm{v})$ dengan intensitas naungan $80 \%$ di persemaian.

\section{UCAPAN TERIMA KASIH}

Penulis menyampaikan terimakasih kepada Balai Litbang Teknologi Agroforestri yang telah memberikan kesempatan serta dana sehingga penelitian ini dapat terlaksana. Penulis juga menyampaikan terimakasih kepada Universitas Siliwangi dan rekan rekan yang tidak dapat disebutkan satu persatu satu yang telah membantu dalam proses pelaksanaan penelitian.

\section{4}

\section{DAFTAR PUSTAKA}

Adinandra, R., \& Pujianto, T. (2020). Analisis sistem produksi kopi menggunakan Good Agriculture Practices. Jurnal Ekonomi Pertanian Dan Agribisnis, 4(2), 288-297.

Alridiwirsah, Hamidah, H., Erwin, M. H., \& Muchtar, Y. (2015). Uji toleransi beberapa varietas padi (Oryza sativa L.) terhadap naungan. Jurnal Pertanian Tropik, 2(2), 93101.

Anam, C. (2015). Pengaruh macam media tanam dan macam naungan terhadap pertumbuhan bibit jahe merah (Zingiber officinale Var. rubrum). Saintis, 7(2), 123-135.

Bariyyah, K., Suparjono, S., \& Usmadi. (2015). Pengaruh kombinasi komposisi media organik dan konsentrasi nutrisi terhadap daya hasil tanaman melon (Cucumis melo L.). Planta Tropika Journal of Agro Science, 3(2), 67-71.

Danu, \& Kurniaty, R. (2013). Pengaruh media dan naungan terhadap pertumbuhan pembibitan gerunggang (Cratoxylom arborescens Blume). Junal Perbenihan Tanaman Hutan, 1(1), 43-50.

Direktorat Jenderal Perkebunan. (2020). Statistik Perkebunan Unggulan Nasional.

Evizal, R., Tohari, Prijambada, I. D., \& Widada, J. (2012). Peranana pohon pelindung dalam menentukan produktivitas kopi. Jurnal Agrotropika, 17(1), 19-23.

Gomez, K. ., \& Gomez, A. A. (1995). Prosedur Statistik Untuk Penelitian Pertanian (Edisi II). Jakarta: Universitas Indonesia (UI Press).

Harahap, A. D., Nurhidayah, T., \& Saputra, S. I. (2015). Pengaruh pemberian kompos ampas tahu terhadap pertumbuhan bibit kopi robusta (Coffea canephora pierre) di bawah naungan tanaman kelapa sawit. JOM FAPERTA, 2(112).

Mahasidhi, N. M. S. G., \& Prijono, S. (2021). Intersepse dan aliran batang tanaman kopi dengan berbagai naungan di Sumbermanjing Wetan Malang. Jurnal Tanah Dan Sumberdaya Lahan, 8(1), 115-121.

Muningsih, R., Putri, L. F. A., \& Subantoro, R. (2018). Pertumbuhan stek bibit kopi dengan perbedaan jumlah ruas pada media tanah- 
kompos. MEDIAGRO, 14(2), 64-71.

Nurkhasanah, N., Wicaksono, K. P., \& Widaryanto, E. (2013). Studi pemberian air dan tingkat naungan terhadap pertumbuhan bibit tanaman cabe jamu (Piper retrofractum Vahl.). Jurnal Produksi Tanaman, 1(4), 325-332.

Pramono, A. A., \& Siregar, N. (2015). Pengaruh naungan, zat pengatur tumbuh dan tanaman induk terhadap perakaran stek jabon (Anthocephalus cadamba). Jurnal Perbenihan Tanaman Hutan, 3(2), 71-79.

Pratiwi, A. M., Kaskayo, H., Herwanti, S., \& Qurniati, R. (2019). Saluran pemasaran kopi robusta (Coffea robusta) di agroforestri Pekon Air Kubang, Kecamatan Air Naningan, Kabupaten Tanggamus. Jurnal Belantara, 2(2), 76-83.

Pratiwi, N. E., Simanjuntak, B. H., \& Banjarnahor, D. (2017). Pengaruh campuran media tanam terhadap pertumbuhan tanaman stroberi (Fragaria vesca L.) sebagai tanaman hias teman vertikal. AGRIC, 29(1), 11-20.

Priyadarshini, Hairiah, K., Suprayogo, D., \& Baon, J. B. (2011). Keragaman pohon penaung pada kopi berbasis agroforestri dan pengaruhnya terhadap layanan ekosistem. Berkala Penelitian Hayati, Edisi Khusus(7 F), 81-85.

Qifli, A. K. M., Hairiah, K., \& Suprayogo, D. (2014). Studi nitrifikasi tanah dengan penambahan seresah asal hutan alami dan agroforestri kopi. Jurnal Tanah Dan Sumberdaya Lahan, 1(2), 15-24.

Safitri, E., Purbajanti, E. D., \& Karno. (2020). Pertumbuhan tanaman bambu hias (Dracaena sanderiana) dengan intensitas naungan yang berbeda dan berbagai media tanam. J.Agro Complex, 4(2), 132-142.

Saleh, A. R., \& Jayanti, K. D. (2017). Pengaruh populasi naungan terhadap pertumbuhan awal tanaman kakao (Theobroma cacao L.) di lapangan. Jurnal AgroPet, 14(2), 61-70.

Sari, R. R., Marliah, A., \& Hereri, A. I. (2019). Pengaruh komposisi media tanam dan dosis NPK terhadap pertumbuhan bibit kopi robusta (Coffea chanephora L.). Jurnal Agrium, 16(1), 28-37.

Sembiring, L. K. B., Sipayung, R., \& Irsal. (2018). Tanggap pertumbuhan bibit kopi robusta (Coffea robusta L.) terhadap berbagai media tanam dan frekuensi penyiraman. Jurnal Pertanian Tropik, 20, 158-169.

Sitanggang, A., Isnan, \& Saputra, S. I. (2015). Pengaruh pemberian pupuk kandang ayam dan zat pengatur tumbuh giberelin terhadap pertumbuhan bibit kopi arabika (Coffea arabica L.). JOM FAPERTA, 2(1), 1-12.

Suherman. (2015). Keragaman stomata daun kopi pada berbagai pohon penaung sistem agroforestri. Jurnal Galung Tropika, 4(1), 16.

Supriadi, H., \& Pranowo, D. (2015). Prospek pengembangan agroforestri berbasis kopi di Indonesia. Perspektif, 14(2), 135-150.

Syahadat, R. M., \& Aziz, S. A. (2012). Pengaruh komposisi media dan fertigasi pupuk organik terhadap kandungan bioaktif daun tanaman kemuning (Murraya paniculata JACK) di pembibbitan. Buletin Penelitian Tanaman Rempah Dan Obat, 23(2), 142-147.

Wachjar, A., Setiadi, Y., \& Mardhikanto, L. W. (2002). No TitlePengaruh pupuk organik dan intensitas naungan terhadap pertumbuhan bibit kopi robusta (Coffee canephora Pierre). Buletin Agronomi, 30(1), 6-11. 